\title{
Demodex-associated bacterial proteins induce neutrophil activation
}

\author{
N. O’Reilly, ${ }^{\star}$ D. Bergin, $\dagger$ E.P. Reeves, $\dagger$ N.G. McElvaney $\dagger$ and K. Kavanagh* \\ *Medical Mycology Unit, Department of Biology, National University of Ireland Maynooth, Co. Kildare, Ireland \\ $†$ Tespiratory Research Division, Department of Medicine, Royal College of Surgeons in Ireland, Beaumont Hospital, Dublin 9, Ireland
}

\section{Summary}

\section{Correspondence \\ Kevin Kavanagh. \\ E-mail: kevin.kavanagh@nuim.ie}

\section{Accepted for publication \\ 14 November 2011}

\section{Funding sources \\ None.}

\section{Conflicts of interest \\ None declared.}

DOI $10.1111 / j .1365-2133.2011 .10746 . x$
Background Patients with rosacea demonstrate a higher density of Demodex mites in their skin than do controls. A bacterium isolated from a Demodex mite from a patient with papulopustular rosacea (PPR) was previously shown to provoke an immune response in patients with PPR or ocular rosacea, thus suggesting a possible role for bacterial proteins in the aetiology of this condition.

Objectives To examine the response of neutrophils to proteins derived from a bacterium isolated from a Demodex mite.

Methods Bacterial cells were lysed and proteins were partially purified by ÄKTA fast protein liquid chromatography. Isolated neutrophils were exposed to bacterial proteins and monitored for alterations in migration, degranulation and cytokine production.

Results Neutrophils exposed to proteins from Bacillus cells demonstrated increased levels of migration and elevated release of matrix metalloprotease 9, an enzyme known to degrade collagen, and cathelicidin, an antimicrobial peptide. In addition, neutrophils exposed to the bacterial proteins demonstrated elevated rates of interleukin 8 and tumour necrosis factor- $\alpha$ production.

Conclusions Proteins produced by a bacterium isolated from a Demodex mite have the ability to increase the migration, degranulation and cytokine production abilities of neutrophils. These results suggest that bacteria may play a role in the inflammatory erythema associated with rosacea.
Rosacea is a chronic inflammatory dermatosis that affects primarily the skin of the central regions of the face. ${ }^{1}$ A number of forms of this condition are recognized, including papulopustular, erythematotelagiectatic, ocular and phymatous. ${ }^{2}$ Factors such as alterations in the innate immune response, vascular changes in the skin and the presence of reactive oxygen species (ROS) within the skin have been suggested as playing a role in the induction and persistence of the condition. ${ }^{3}$

Neutrophils play a critical role in the innate immune system by phagocytosing, killing and digesting microbial cells ${ }^{4}$ and have been implicated in the pathogenesis of rosacea. ${ }^{5}$ Oxidative mechanisms of microbial killing are dependent upon the production of ROS, triggered by activation of the NADPH oxidase. ${ }^{6}$ Many of the agents used to control rosacea, such as tetracyclines, azelaic acid, retinoids and metronidazole, ${ }^{7-9}$ inhibit ROS production and lead to clearance of rosacea, thus suggesting a central role for neutrophils in the condition. Neutrophils can also induce tissue damage by the release of proteolytic enzymes that can degrade collagen, ${ }^{10,11}$ as well as activating key signalling pathways ${ }^{12,13}$ that result in increased inflammation.

Antibiotics such as metronidazole, tetracyclines and erythromycin, which are employed to control rosacea, indicate a potential role for bacteria in the aetiology of the condition, although it has been suggested that these antibiotics may act primarily as anti-inflammatory agents rather than by inhibiting a specific bacterium. ${ }^{14}$ Staphylococcus epidermidis isolated from patients with rosacea (but not controls) were consistently $\beta$-haemolytic and grew better at $37{ }^{\circ} \mathrm{C}$ than at $30{ }^{\circ} \mathrm{C}$, suggesting a link between mesophilic hydrolytic bacteria and rosacea. ${ }^{15}$ In addition, this bacterium has been isolated from the pustules of patients with papulopustular rosacea and from the eyelids of patients with ocular rosacea, indicating a possible role for this bacterium in the induction of these conditions. ${ }^{16}$

Patients affected with rosacea display a higher density of facial mites, Demodex folliculorum, than unaffected controls. ${ }^{17-19}$ A bacterium (Bacillus oleronius) isolated from a D. folliculorum mite 
from a patient with rosacea produced proteins that induced an inflammatory immune response in $72 \%$ of patients with papulopustular rosacea, but in only $29 \%$ of controls $(P=0 \cdot 01) .{ }^{20}$ The bacterium was previously isolated from the digestive tract of a termite, where it plays a role in facilitating digestion, ${ }^{21}$ and it was postulated that the bacterium may play a similar role in the digestive tract of Demodex. ${ }^{20}$ Recently, a strong correlation has been established between serum reactivity to these Bacillus proteins and eyelid margin inflammation $(P=0.04)$ and ocular rosacea $(\mathrm{P}=0.01) .{ }^{22}$

The aim of the work presented here was to investigate the response of neutrophils to proteins from $B$. oleronius because it was hypothesized that these proteins could stimulate neutrophils and so lead to localized inflammation in vivo.

\section{Materials and methods}

\section{Preparation of bacterial proteins}

Proteins were extracted from B. oleronius cells as described previously. ${ }^{20}$ The protein concentration was determined by Bradford assay and this material was termed 'crude' protein preparation. The crude protein preparation was diluted in phosphate-buffered saline (PBS) to a concentration of $200 \mu \mathrm{g} \mathrm{mL}^{-1}$ and stored at $-20{ }^{\circ} \mathrm{C}$. The crude preparation was purified by anion exchange separation by ÄKTA fast protein liquid chromatography (ÄKTAFPLC ${ }^{\mathrm{TM}}$, GE Healthcare, Little Chalfont, U.K.) as described. ${ }^{20}$ Fractions corresponding to the proteins of interest were pooled, precipitated (termed 'purified' protein preparation) and resuspended in PBS at a concentration of $200 \mu \mathrm{g} \mathrm{mL}^{-1}$. Proteins were resolved by one-dimensional sodium dodecyl sulphate-polyacrylamide gel electrophoresis (1-D SDS-PAGE) and stained with colloidal Coomassie blue to visualize.

\section{Protein identification}

Gel pieces corresponding to protein bands were excised and trypsin digested as described. ${ }^{23}$ Following peptide extraction, identification was performed using an Agilent 6340 Ion Trap LC/MS (Agilent Technologies, Santa Clara, CA, U.S.A.), calibrated using bovine serum albumin (Table 1). The resulting mass lists were Basic Local Alignment Search Tool (BLAST) searched using the Mascot MS/MS Ion Search program, available at http://www.matrixscience.com (accessed 11 January 2012). Annotated function and protein information was ascertained through the UniProt database (http://www. uniprot.org) (accessed 11 January 2012). A Mascot score $>67$ was considered significant at $P<0.05$.

\section{Isolation of neutrophils}

Human neutrophils were isolated from healthy volunteers by dextran sedimentation and Ficoll-Hypaque centrifugation (Axis-Shield PoC AS, Oslo, Norway) as previously described. ${ }^{24}$ Viability was assessed using the trypan blue exclusion assay. ${ }^{25}$

\section{Neutrophil migration assay}

Neutrophils $\left(1 \times 10^{6} \mathrm{~mL}^{-1}\right)$ were resuspended in RPMI-1640 medium containing $2 \mathrm{mmol} \mathrm{L}^{-1}$ L-glutamine and $5 \%$ fetal calf serum (FCS). Cells were treated with the bacterial protein (2 and $6 \mu \mathrm{g} \mathrm{mL}^{-1}$ of the purified or $2 \mu \mathrm{g} \mathrm{mL}^{-1}$ of the crude preparation) for $1 \mathrm{~h}$. A $3-\mu \mathrm{m}$ porous insert (BD Falcon ${ }^{\mathrm{TM}}, \mathrm{BD}$, Franklin Lakes, NJ, U.S.A.) was added to each well of a 24 well plate containing medium $(500 \mu \mathrm{L})$ with the protein preparation. Neutrophils in medium $(500 \mu \mathrm{L})$ containing the bacterial proteins were added into the insert and the plate was incubated for $24 \mathrm{~h}$ in a humidified $5 \% \mathrm{CO}_{2}$ incubator at $37{ }^{\circ} \mathrm{C}$. Inserts were removed and washed three times with PBS before staining with crystal violet $(0 \cdot 25 \% \mathrm{w} / \mathrm{v})$. The cells were eluted using glacial acetic acid $(33 \% \mathrm{v} / \mathrm{v})$ and the absorbance was measured at $570 \mathrm{~nm}$ using a BioTek plate reader (BioTek, Winooski, VT, U.S.A.) as an indicator of neutrophil migration.

\section{Quantification of release of matrix metalloprotease 9 and cathelicidin}

Neutrophils $\left(1 \times 10^{7} \mathrm{~mL}^{-1}\right)$ were resuspended in PBS containing $5 \mathrm{mmol} \mathrm{L}^{-1}$ glucose and protease inhibitors as described. Following co-incubation with Bacillus protein preparations (crude or purified) in a stirred chamber at $37^{\circ} \mathrm{C}$, an aliquot was removed at $\mathrm{t}=0,3,6$ and $9 \mathrm{~min}$. Cells were removed by centrifugation $(800 \mathrm{~g})$. The protein content of the supernatant was precipitated and prepared for electrophoresis and immunoblotting.

Samples were separated by 1-D SDS-PAGE [12.5\% (w/v) acrylamide]. For Western blotting, the protein was transferred to a nitrocellulose membrane using a wet blotter at $100 \mathrm{~V}$ for 70 min. Membranes were incubated in the primary antibodies diluted 1: 1000 overnight at $4{ }^{\circ} \mathrm{C}$. Matrix metalloprotease (MMP)-9 antiserum raised in goat (GenWay Biotech, Inc., San Diego, CA, U.S.A.) and human cathelicidin antimicrobial protein (hCAP-18)/LL-37 antiserum raised in rabbit (Lonza, Basel, Switzerland) were employed. Membranes were incubated in the secondary antibodies for $2 \mathrm{~h}$ at room temperature. Horseradish peroxidase (HRP)-linked goat antiserum at a dilution of 1 : 5000 was used with the MMP-9 blots and HRP-linked rabbit antiserum at a dilution of $1: 1000$ was used for the hCAP-18 blots. Enhanced chemiluminescence (PerkinElmer, Waltham, MA, U.S.A.) was employed to develop reactive protein bands and the intensity of immunobands was quantified by densitometry using ImageJ software (NIH, Bethesda, MD, U.S.A.).

\section{Cytokine determination by enzyme-linked immunosorbent assay}

Isolated neutrophils $\left(1 \times 10^{6} \mathrm{~mL}^{-1}\right.$ in RPMI-1640 media containing $2 \mathrm{mmol} \mathrm{L}^{-1}$ L-glutamine and 5\% FCS) were added to each well of 24-well flat-bottomed tissue culture plates (BD Falcon $^{\mathrm{TM}}$ ) and incubated for 3, 15 and $24 \mathrm{~h}$. Cells were treated with 2 and $6 \mu \mathrm{gL}^{-1}$ of purified bacterial protein or 
$2 \mu \mathrm{g} \mathrm{mL}^{-1}$ of crude Bacillus protein preparation. Culture supernatants were harvested at the indicated times and stored at $-80{ }^{\circ} \mathrm{C}$ until assayed. IL- 8 and TNF- $\alpha$ levels were measured using commercial enzyme-linked immunosorbent assay (ELISA) kits (R\&D Systems, Minneapolis, MN, U.S.A. and mini ELISA; PeproTech, Rocky Hill, NJ, U.S.A., respectively) according to the manufacturers' guidelines.

\section{Statistics}

All values are the mean of at least three biological replicates \pm SE. Experimental data were tested for statistical significance at $\mathrm{P}<0.05$ using a Student's t-test with GraphPad Prism 5 (GraphPad Software, La Jolla, CA, U.S.A.); * is used to denote $\mathrm{P}<0.05$, while $* *$ denotes $\mathrm{P}<0.01$.

\section{Results}

\section{Isolation and purification of Bacillus oleronius proteins}

It has been previously demonstrated that B. oleronius produces proteins that induce immune reactivity in patients with rosacea. $^{20,22}$ To analyse the effect of this bacterium on neutrophils, a whole cell lysate was prepared and purified using ÄKTAFPLC ${ }^{\mathrm{TM}}$ (GE Healthcare). Due to the nature of the purification method, several proteins were present in the preparation, as evidenced by resolving the sample on an SDS-PAGE gel (Fig. 1). Selected protein bands (29) were excised and prepared for identification as described. A number of these proteins (Table 1) had well characterized abilities to interact with and stimulate an immune response. One of the proteins present in the preparation was identified as a peptidoglycan synthesis protein (band 5): peptidoglycan is a well characterized trigger for the innate immune response. ${ }^{26,27}$ Band 20 was identified as flagellin, which is a ligand for TLR-5; activa- tion of this pathway leads to production of cytokines such as IL-8. ${ }^{28-30} \mathrm{~A}$ number of the proteins identified in the purified fraction of the Bacillus lysate were involved in the bacterial response to oxidative stress including Kat E1 (band 4), vegetative catalase 1 (band 8), superoxide dismutase (band 24) and alkyl hydroperoxide reductase (small subunit) (band 26). Catalases (band 8) have been previously identified as being immunoreactive in human sera, ${ }^{31}$ while alkyl hydroperoxide reductase from Helicobacter pylori is known to provoke a strong immune response in mammals. ${ }^{32}$ Elongation factor G (band 12) was also among the identified proteins: several studies have reported proteins with elongation and translational functions as antigenic. ${ }^{33-35}$

\section{Effect of Bacillus oleronius antigens on neutrophil migration}

Neutrophil migration assays were performed to examine if the Bacillus proteins could act as chemo-attractants and thus result in increased neutrophil migration in vitro. The results (Fig. 2) demonstrate that B. oleronius protein treated cells migrate through the $3-\mu \mathrm{m}$ porous inserts at a higher rate than control cells. Cells exposed to $2 \mathrm{mg} \mathrm{mL}^{-1}$ of purified Bacillus protein migrated at four times the rate through $3-\mu \mathrm{m}$ pores compared with controls. Those cells exposed to the $2 \mathrm{mg} \mathrm{mL}^{-1}$ crude protein preparation migrated at a rate six times greater than controls.

\section{Effect of Bacillus oleronius antigens on neutrophil- mediated degranulation}

Degranulation is an intrinsic part of the killing mechanism of neutrophils and serves to eliminate phagocytosed microbes. Healthy control neutrophils were exposed to the B. oleronius protein preparations, and cell-free supernatants were isolated

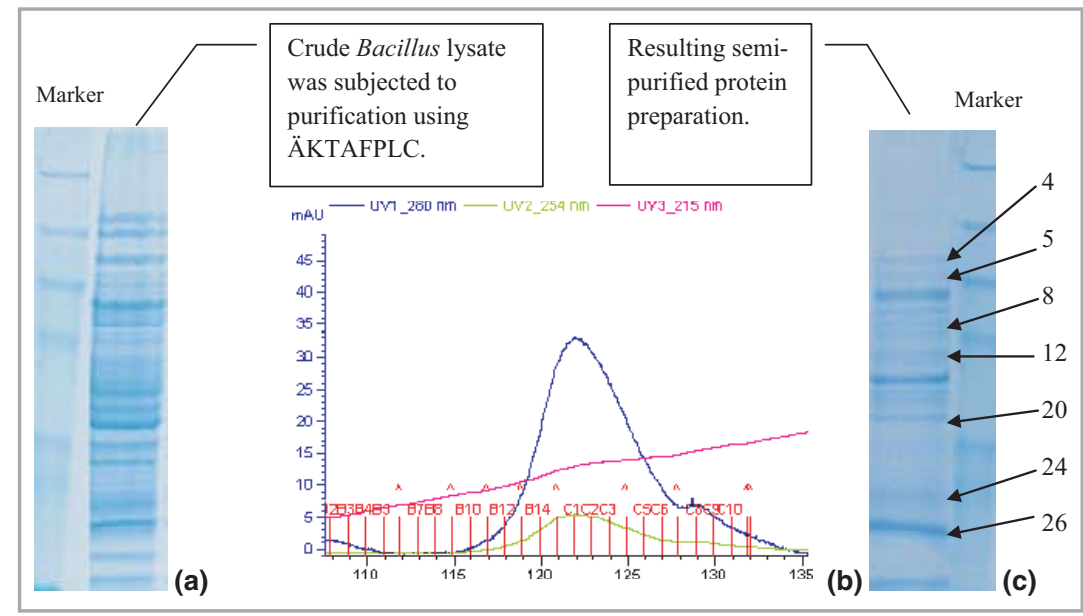

Fig 1. (a) One-dimensional sodium dodecyl sulphate-polyacrylamide gel electrophoresis (1-D SDS-PAGE) of Bacillus oleronius. (b) Chromatograph from ÄKTA fast protein liquid chromatography ( $\ddot{\text { KTAFPLC }}{ }^{\mathrm{TM}}$ ), where the $x$-axis represents time in minutes and the $y$-axis represents absorbance at $280 \mathrm{~nm}$. The red markings represent $500-\mu \mathrm{L}$ fractions collected at 1-min intervals during elution. The fractions corresponding to the peak (B12C10) were concentrated using Centricon tubes. (c) Resulting semipurified protein preparation subjected to 1-D SDS-PAGE, where numbered bands had proteins with antigenic properties. 
Table 1 Bacillus oleronius protein bands identified by LC/MS

\begin{tabular}{|c|c|c|c|c|c|c|c|}
\hline Protein & Band & $\begin{array}{l}\text { Mass } \\
(\mathrm{kDa})\end{array}$ & Mascot Score & $\begin{array}{l}\mathrm{pI} \\
\text { value }\end{array}$ & $\begin{array}{l}\text { Coverage } \\
(\%)\end{array}$ & $\begin{array}{l}\text { Accession } \\
\text { number }\end{array}$ & UniProt function \\
\hline KatE1 & 4 & $54 \cdot 5$ & 181 & $5 \cdot 48$ & 7 & YP_093702 & $\begin{array}{l}\text { Involved in the response to } \\
\text { oxidative stress often resulting } \\
\text { from exposure to high levels of } \\
\text { reactive oxygen species, e.g. } \\
\text { superoxide anions, hydrogen } \\
\text { peroxide, and hydroxyl radicals }\end{array}$ \\
\hline $\begin{array}{l}\text { Hypothetical } \\
\text { protein Noc_2222 }\end{array}$ & 5 & $40 \cdot 1$ & 71 & $5 \cdot 63$ & 4 & YP_344212 & $\begin{array}{l}\text { Peptidoglycan biosynthetic } \\
\text { process } \\
\text { ATP binding }\end{array}$ \\
\hline Vegetative catalase 1 & 8 & $54 \cdot 8$ & 287 & $6 \cdot 03$ & 22 & YP_081190 & $\begin{array}{l}\text { Decomposes hydrogen peroxide } \\
\text { into water and oxygen; serves } \\
\text { to protect cells from the toxic } \\
\text { effects of hydrogen peroxide }\end{array}$ \\
\hline Elongation factor $\mathrm{G}$ & 12 & $76 \cdot 4$ & 189 & $4 \cdot 83$ & 9 & YP_077397 & $\begin{array}{l}\text { Catalyses the GTP-dependent } \\
\text { ribosomal translocation step } \\
\text { during translation elongation }\end{array}$ \\
\hline Flagellin & 20 & $26 \cdot 5$ & 189 & $5 \cdot 09$ & 20 & BAB58982 & Ciliary or flagellar motility \\
\hline Superoxide dismutase & 24 & $22 \cdot 5$ & 171 & $5 \cdot 33$ & 25 & YP_079829 & $\begin{array}{l}\text { Destroys radicals normally } \\
\text { produced within the cells and } \\
\text { toxic to biological systems }\end{array}$ \\
\hline $\begin{array}{l}\text { Alkyl hydroperoxide } \\
\text { reductase (small subunit) }\end{array}$ & 26 & $20 \cdot 8$ & 237 & $4 \cdot 66$ & 27 & YP_081364 & $\begin{array}{l}\text { Involved in maintenance of the } \\
\text { redox environment of a cell or } \\
\text { a compartment within the cell }\end{array}$ \\
\hline
\end{tabular}

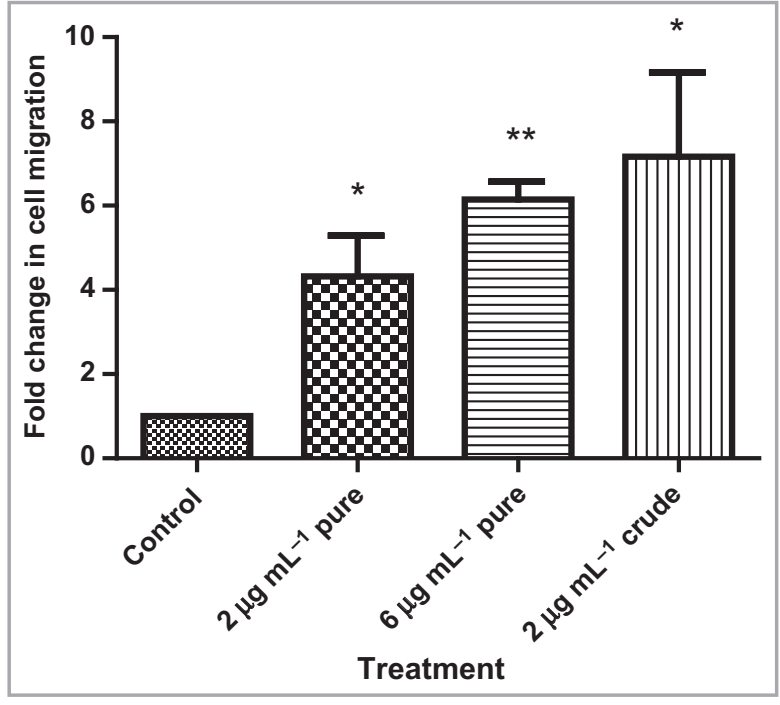

Fig 2. The effect of B. oleronius proteins on migration of human neutrophils through $3-\mu \mathrm{m}$ porous inserts. The results are presented as a fold change in cell density compared with control, where a significant increase of $\mathrm{P}<0.05$ is denoted by $*$ and $\mathrm{P}<0.01$ is denoted by **.

and resolved by 1-D SDS-PAGE. Western blot analysis of these supernatants demonstrated there was an increase in the levels of MMP-9 secreted by neutrophils during degranulation when treated with the Bacillus antigens (Fig. 3a,b). There was a 2.9fold increase in release of MMP-9 from neutrophils treated with $2 \mu \mathrm{g} \mathrm{mL}^{-1}$ of the purified antigen after $3 \mathrm{~min}$ when compared with the controls $(P=0.001)$. Following 6 min of exposure to bacterial proteins, expression of hCAP-18 by neutrophils increased by $2 \cdot 4$-fold $(P=0.04)$ compared with control cells (Fig. 4a,b). These results indicate that exposure of neutrophils to the crude or purified B. oleronius protein preparations leads to significantly elevated rates of degranulation as measured by the release of MMP-9 and cathelicidin, which in vivo could damage surrounding tissue. ${ }^{10,11,36}$

\section{Bacillus oleronius proteins stimulate the production of inflammatory cytokines by neutrophils}

Cytokine production and release by neutrophils is an essential part of the inflammatory process at sites of injury. The chemokine IL- 8 has a major role in recruiting circulating neutrophils to inflammatory sites and the cytokine TNF- $\alpha$ is known to be produced by neutrophils during inflammation triggered by bacterial proteins. ${ }^{37-39}$ We evaluated the ability of B. oleronius proteins to induce neutrophil production of IL- 8 and TNF- $\alpha$ over $24 \mathrm{~h}$. Neutrophils exposed to Bacillus proteins demonstrated a significant increase in IL-8 production compared with controls. The greatest increase was evident in neutrophils exposed to the crude Bacillus protein preparation for $16 \mathrm{~h}$ where a $2 \cdot 7$-fold increase was observed $(P=0.003)$ (Fig. 5a). The greatest increase in TNF- $\alpha$ production was evident in neu- 
Fig 3. Visualization of anti-matrix metalloprotease (MMP)-9 reactivity in secretome of neutrophils exposed to Bacillus protein preparation for $0,3,6$ and $9 \mathrm{~min}$. The graph (b) represents densitometric analysis of the blots (a) using ImageJ software. There is a significant increase in reactivity of the anti-MMP-9 antibody to the secretome of neutrophils treated with PMA (positive control) or B. oleronius protein preparation (pure or crude). ${ }^{*}$ denotes that the treatment means are significantly different at $\mathrm{P}<0.05$ and $* *$ denotes significant difference at $P<0.01$ relative to the control at the appropriate time point. PMA, phosphomolybdic acid.

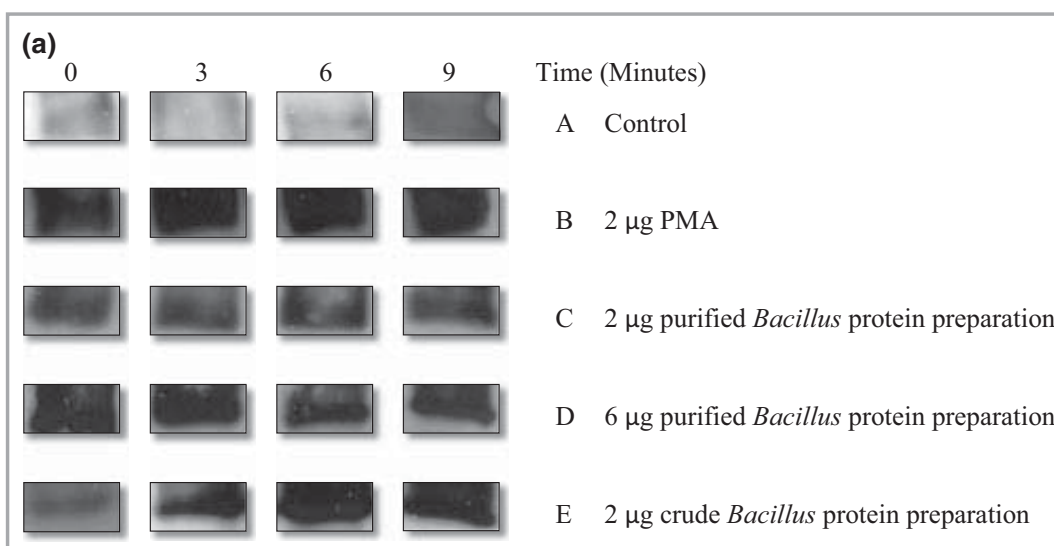

(b) $200000 \%$ Contro

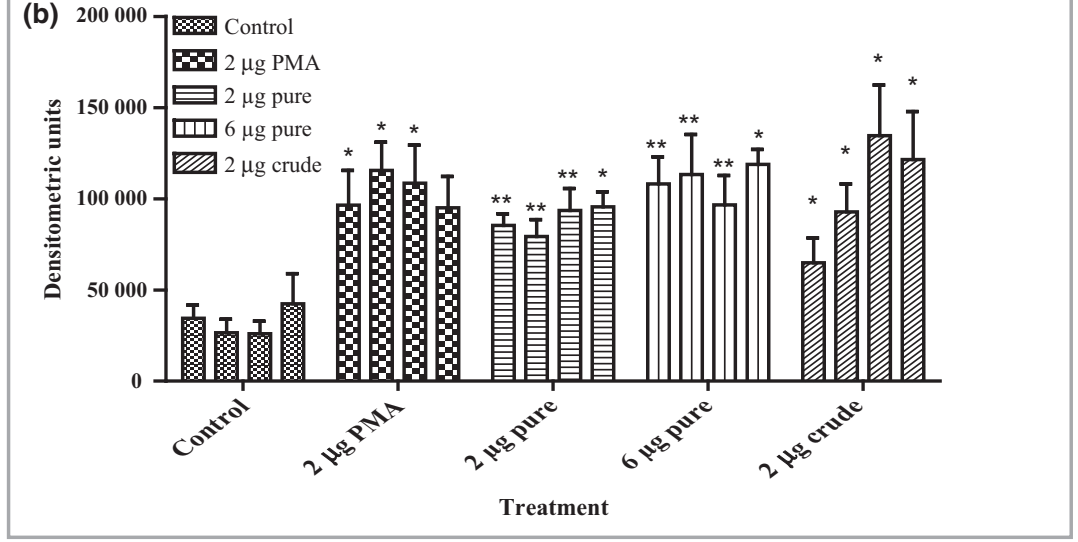

Fig 4. (a) Visualization of anti-hCAP-18 (cathelicidin) reactivity in secretome of neutrophils exposed to Bacillus protein preparation for 0, 3, 6 and $9 \mathrm{~min}$. The graph (b) represents densitometric analysis of the blots (a) using ImageJ software. There is a significant increase in reactivity of the hCAP18 antibody to the secretome of neutrophils treated with PMA (positive control) or B. oleronius protein preparation (pure or crude). * denotes that the treatment means are significantly different at $\mathrm{P}<0.05$ and $* *$ denotes significant difference at $\mathrm{P}<0.01$ relative to the control at the appropriate time point. PMA, phosphomolybdic acid. 


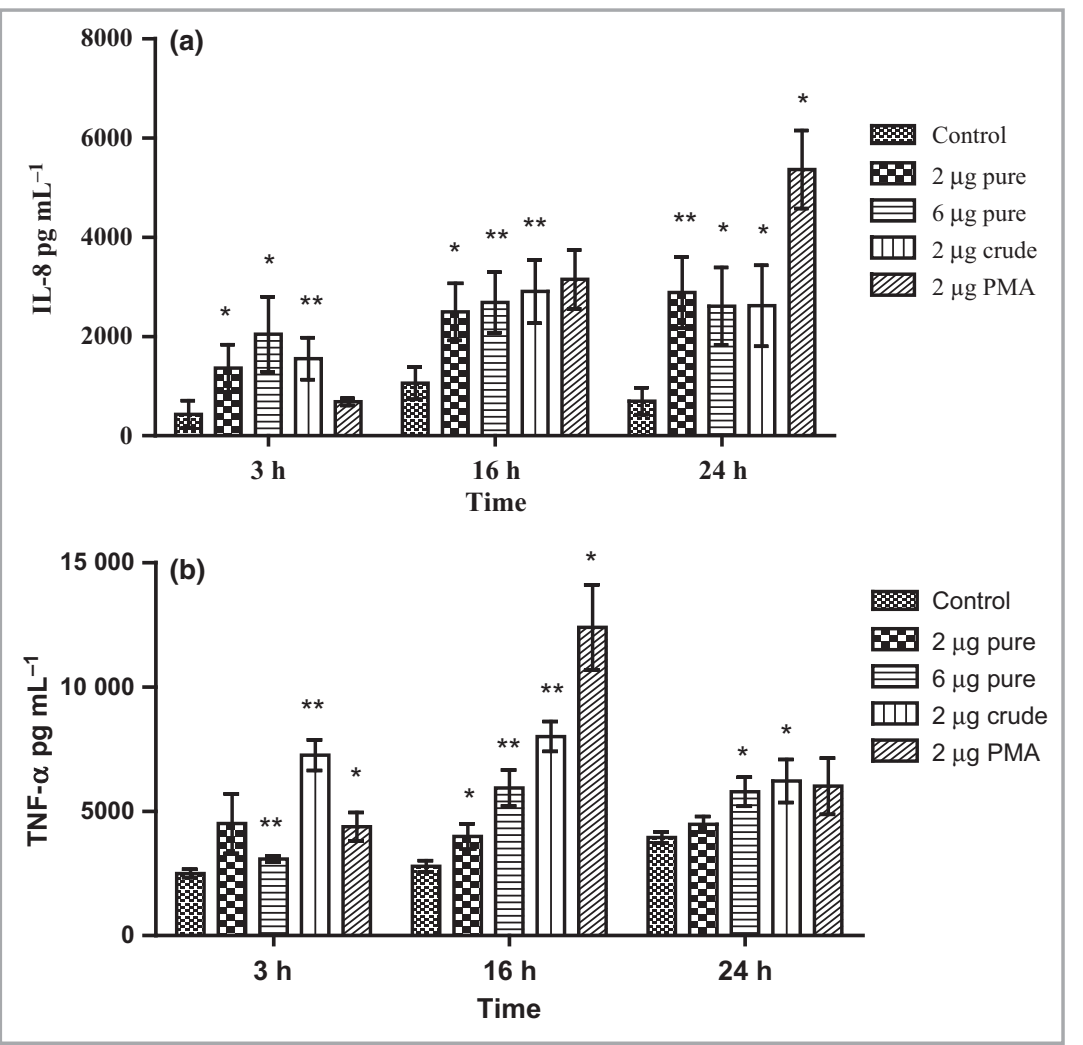

Fig 5. (a) The effect of B. oleronius proteins on interleukin (IL) 8 secretion by human neutrophils. The results are expressed as pg $\mathrm{mL}^{-1}$ of cytokine. (b) The effect of B. oleronius proteins on tumour necrosis factor (TNF) $\alpha$ secretion by human neutrophils, expressed as pg $\mathrm{mL}^{-1}$ of cytokine. The results represent three biological replicates of the assay where $*$ denotes that the treatment means are significantly different at $\mathrm{P}<0.05$ and $* *$ denotes highly significant difference at $\mathrm{P}<0.01$. PMA, phosphomolybdic acid. trophils exposed to $2 \mu \mathrm{g} \mathrm{mL}^{-1}$ crude Bacillus protein preparation for $3 \mathrm{~h}(2 \cdot 9$-fold increase, $\mathrm{P}<0.001)$ or $16 \mathrm{~h}$ ( $2 \cdot 8$-fold increase, $\mathrm{P}<0.001$ ) (Fig. 5b).

\section{Discussion}

The significance of the elevated density of Demodex mites on the faces of patients with rosacea ${ }^{18,19,40}$ has been the subject of much speculation. Recent work has demonstrated that a bacterium isolated from a Demodex mite from the face of a patient with papulopustular rosacea produced proteins that stimulate an immune response in patients with papulopustular ${ }^{20}$ or ocular rosacea. ${ }^{22}$ The current work sought to characterize the effects of these Demodex-associated Bacillus proteins on the host's immune response by characterizing the effect on neutrophils, which have previously been implicated in the pathogenesis of rosacea. ${ }^{7,8}$

Bacillus cell lysates contain a wide range of immunogenic proteins, which could interact with and activate the immune response in the skin of patients with rosacea (Table 1). Exposure of neutrophils to proteins from B. oleronius leads to increased migration (Fig. 2), which could be significant in vivo because it would suggest an increase in movement of neutrophils in an area high in these proteins. Neutrophils exposed to the Bacillus proteins were also shown to degranulate, as measured by the release of MMP-9 (Fig. 3) and cathelicidin (Fig. 4), and to produce the inflammatory cytokines IL-8 and TNF- $\alpha$ (Fig. 5a,b). The production of the cytokines indicates that further neutrophil recruitment to the site is possible as well as further TNF- $\boldsymbol{\alpha}$-induced inflammation.
One potential scenario linking the presence of B. oleronius immune stimulatory proteins in Demodex mites to the symptoms of rosacea is dependent upon high mite density. As the Demodex mites die in the pilosebaceous unit they would release the Bacillus cells and associated proteins. The released bacterial proteins could leak from the unit and attract neutrophils to the affected areas, which would then degranulate, releasing MMP-9 and cathelicidin in the tissue adjacent to the pilosebaceous unit, causing tissue degradation and inflammation. Furthermore, these proteins induce the production of inflammatory cytokines/chemokines by neutrophils; this would maintain the inflammation observed in patients with rosacea, causing increased neutrophil influx towards the pilosebaceous unit. The activation of neutrophils would result in excessive inflammation and tissue damage in the affected areas. ${ }^{10-12,36,41,42}$ Antibiotic therapy (e.g. metronidazole or tetracycline) used in the treatment of rosacea would kill the Bacillus in the Demodex mites; thus no new bacterial cells/proteins would be released from the mites after a period of time. It is well established that, following cessation of antibiotic therapy, the symptoms of rosacea gradually return over a period of time. ${ }^{14}$ We speculate that this may be due to a gradual increase in the population of Demodex mites in the skin, leading to release of bacterial proteins and once again stimulating neutrophil migration and inflammation.

It is postulated that B. oleronius may be one of a number of bacteria that reside in the digestive tract of the Demodex mite. ${ }^{20}$ Demodex mites are unique in the animal kingdom in lacking an anus; consequently they cannot void waste material. ${ }^{43,44}$ It is 
possible that the mite requires a range of bacteria to assist in the digestion of food and that these build up to high levels in the digestive tract before being released following the death of the mite. The elevated mite density in patients with rosacea leads to the release of large amounts of stimulatory proteins, which may leak from the pilosebaceous unit and attract neutrophils, which in turn leads to inflammation and tissue damage. This hypothesis might explain why papulopustular rosacea in particular often demonstrates a follicular-oriented inflammation.

It is clear that rosacea is a multifactorial disease and involves environmental, immunological, microbiological and dermatological components. ${ }^{3,14}$ While the results presented here do not explain the aetiology of rosacea, they do offer an insight into how an elevated Demodex density could play a role in the induction of tissue damage and explain why antibiotic treatment leads to a reduction in symptoms without immediately reducing mite numbers. The elevated release of cathelicidin antimicrobial peptides ${ }^{45}$ may also facilitate an enhanced immune response to the released proteins. A greater understanding of the factors that contribute to the onset and persistence of rosacea will allow the development of more effective therapies.

\section{What's already known about this topic?}

- Patients with Rosacea demonstrate a higher density of Demodex mites in their skin than controls. The role of these mites in the induction of rosacea is unclear.

\section{What does this study add?}

- This study demonstrates that proteins from a bacterium (Bacillus oleronius) from a Demodex mite originally isolated from a patient with rosacea activate neutrophils and thus may play a role in the induction of the inflammation and tissue degradation associated with this condition.

\section{Acknowledgment}

N. O'Reilly is the recipient of a John and Pat Hume Scholarship from National University of Ireland, Maynooth.

\section{References}

1 Powell FC. Rosacea. N Engl J Med 2005; 352:793-803.

2 Wilkin J, Dahl M, Detmar M et al. Standard classification of rosacea: report of the National Rosacea Society Expert Committee on the classification and staging of rosacea. J Am Acad Dermatol 2002; 46:584-7.

3 Yamasaki K, Gallo RL. The molecular pathology of rosacea. J Dermatol Sci 2009; 55:77-81.

4 Bellocchio S, Moretti S, Perrucio K et al. TLRs govern neutrophil activity in aspergillosis. J Immunol 2004; 173:7406-15.

5 Akamatsu H, Oguchi M, Nishijima $S$ et al. The inhibition of free radical generation by human neutrophils through the synergistic effect of metronidazole with palmitoleic acid: a possible mechanism of metronidazole in rosacea and acne. Arch Dermatol Res 1990; 282:449-54.

6 Curnutte JT, Kuver R, Babior BM. Activation of the respiratory burst oxidase in a fully soluble system from human neutrophils. J Biol Chem 1987; 262:6450-2.

7 Miyashi Y, Yoshioka A, Imamura S, Niwa Y. Effect of antibiotics on the generation of reactive oxygen species. J Invest Dermatol 1986; 86:449-53.

8 Akamatsu H, Komura J, Asada Y et al. Inhibitory effect of azelaic acid on neutrophil functions: a possible cause of its efficacy in treating pathogenically unrelated diseases. Arch Dermatol Res 1991; 282:162-6.

9 Yoshioka A, Miyachi Y, Imamura S, Niwa Y. Anti-oxidant effects of retinoids on inflammatory skin diseases. Arch Dermatol Res 1986; 278: $177-83$.

10 Starkey PM, Barrett AJ, Burleigh MC. The degradation of articular collagen by neutrophil proteinases. Biochim Biophys Act 1977; 483:386-97.

11 Berton A, Godeau G, Emonard H et al. Analysis of the ex vivo specificity of human gelatinases A and B towards skin collagen and elastic fibers by computerized morphometry. Matrix Biol 2000; 19:139-48.

12 Devaney JM, Greene CM, Taggart CC et al. Neutrophil elastase upregulates interleukin-8 via toll-like receptor 4. FEBS Lett 2003; 544: 129-32.

13 Kuwahara I, Lillehoj EP, Lu W et al. Neutrophil elastase induces IL8 gene transcription and protein release through p38/NF- $\{$ kappa $\}$ B activation via EGFR transactivation in a lung epithelial cell line. Am J Physiol Lung Cell Mol Physiol 2006; 291:407-16.

14 Gupta AK, Chaudhry MM. Rosacea and its management: an overview. J Eur Acad Dermatol Venereol 2005; 19:273-85.

15 Dahl MV, Ross AJ, Schlievert PM. Temperature regulates bacterial protein production: possible role in rosacea. J Am Acad Dermatol 2004; 50:266-72.

16 Whitfeld M, Gunasingam N, Leow LJ et al. Staphylococcus epidermidis: a possible role in the pustules of rosacea. J Am Acad Dermatol 2011; 64:49-52.

17 Vance J. Demodicidosis: do Demodex mites cause disease? Curr Conc Skin Dis 1986; Spring:10-18.

18 Bonnar E, Eustace P, Powell FC. The Demodex mite population in Rosacea. J Am Acad Dermatol 1993; 28:443-8.

19 Erbagci Z, Ozgoztasi O. The significance of Demodex folliculorum density in rosacea. Int J Dermatol 1998; 37:421-5.

20 Lacey N, Delaney S, Kavanagh K, Powell FC. Mite-related antigens stimulate inflammatory cells in rosacea. Br J Dermatol 2007; 157:474-81.

21 Kuhnigk T, Borst EM, Breunig A et al. Bacillus oleronius sp. nov., a member of the hindgut flora of the termite Reticulitermes santonensis (Feytaud). Can J Microbiol 1995; 41:699-706.

22 Li J, O’Reilly N, Sheha H et al. Correlation between ocular Demodex infestation and serum immunoreactivity to Bacillus microbial proteins in patients with facial rosacea. Opthalmology 2010; 117:870-7.

23 Shevchenko A, Tomas H, Havlis J et al. In-gel digestion for mass spectrometric characterization of proteins and proteomes. Nat Protoc 2006; 1:2856-60.

24 Reeves EP, Lu H, Jacobs HL et al. Killing activity of neutrophils is mediated through activation of proteases by K+ flux. Nature 2002; 416:291-7.

25 Eichner RD, Al Salami M, Wood PR, Müllbacher A. The effect of gliotoxin upon macrophage function. Int J Immunopharmacol 1986; 8:789-97. 
26 Kolonitsiou F, Syrokou A, Karamanos NK et al. Immunoreactivity of $80-\mathrm{kDa}$ peptidoglycan and teichoic acid-like substance of slime producing $S$. epidermidis and specificity of their antibodies studied by an enzyme immunoassay. J Pharm Biomed Anal 2001; 24:429-36.

27 Dziarski R. Peptidoglycan recognition proteins (PGRPs). Mol Immunol 2004; 40:877-86.

28 Eaves-Pyles T, Murthy K, Liaudet L et al. Flagellin, a novel mediator of Salmonella-induced epithelial activation and systemic inflammation: I $\kappa$ B alpha degradation, induction of nitric oxide synthase, induction of proinflammatory mediators, and cardiovascular dysfunction. J Immunol 2001; 166:1248-60.

29 Vance RE, Isberg RR, Portnoy D. Patterns of pathogenesis: discrimination of pathogenic and nonpathogenic microbes by the innate immune system. Cell Host Microbe 2009; 6:10-21.

30 Hozono Y, Ueta M, Hamuro J et al. Human corneal epithelial cells respond to ocular-pathogenic, but not to nonpathogenic-flagellin. Biochem Biophys Res Commun 2006; 347:238-47.

31 Jeavons L, Hamilton AJ, Vanittanakom $\mathrm{N}$ et al. Identification and purification of specific Penicillium marneffei antigens and their recognition by human immune sera. J Clin Microbiol 1998; 36:94954.

32 Yan J, Kumagai T, Ohnishi $M$ et al. Immune response to a 26-kDa protein, alkyl hydroperoxide reductase, in Helicobacter pylori-infected Mongolian gerbil model. Helicobacter 2001; 6:274-82.

33 Shin GW, Palaksha KJ, Kim YR et al. Immunoproteomic analysis of capsulate and non-capsulate strains of Lactococcus garvieae. Vet Microbio 2007; 119:205-12.

34 Shin GW, Nho SW, Park SB et al. Comparison of antigenic proteins from Lactococcus garvieae $\mathrm{KG}-$ and $\mathrm{KG}+$ strains that are recognized by olive flounder (Paralichthys olivaceus) antibodies. Vet Microbiol 2009; 139: 113-20.

35 Lock RA, Coombs GW, McWilliams TM et al. Proteome analysis of highly immunoreactive proteins of Helicobacter pylori. Helicobacter 2002; 7:175-82.
36 Soehnlein O, Oehmcke S, Ma X et al. Neutrophil degranulation mediates severe lung damage triggered by streptococcal M1 protein. Eur Respir J 2008; 32:405-12.

37 Van Dervort AL, Yan L, Madara PJ et al. Nitric oxide regulates endotoxin-induced TNF-alpha production by human neutrophils. J Immunol 1994; 152:4102-9.

38 Lapinet JA, Scapini P, Calzetti F et al. Gene expression and production of tumor necrosis factor alpha, interleukin-1beta (IL-1beta), IL-8, macrophage inflammatory protein 1alpha (MIP-1alpha), MIP1 beta, and gamma interferon-inducible protein 10 by human neutrophils stimulated with group B meningococcal outer membrane vesicles. Infect Immun 2000; 68:6917-23.

39 Sohn EJ, Paape MJ, Connor EE et al. Bacterial lipopolysaccharide stimulates bovine neutrophil production of TNF-alpha, IL-1beta, IL-12 and IFN-gamma. Vet Res 2007; 38:809-18.

40 Forton F, Seys B, Machal JL, Song AM. Demodex folliculorum and topical treatment: acaricidal action evaluated by standardized skin surface biopsy. Br J Dermatol 1998; 138:461-6.

41 Bergin DA, Greene CM, Sterchi EE et al. Activation of the epidermal growth factor receptor (EGFR) by a novel metalloprotease pathway. J Biol Chem 2008; 283:31736-44.

42 Kafienah W, Buttle DJ, Burnett D, Hollander AP. Cleavage of native type I collagen by human neutrophil elastase. Biochem J 1998; 330:897-902.

43 Rufli T, Muncuoglu Y. The hair follicle mites Demodex folliculorum and Demodex brevis: biology and medical importance. A review. Dermatologica 1981; 162:1-11.

44 Nevyas HJ, Nevyas AS. Demodex folliculorum and blepharitis. In: Cutaneous Infestations of Man and Animal (Parish LC, Nutting WB, Schwartzman RM, eds). New York, NY: Praeger, 1983; 209-17.

45 Yamasaki K, Di Nardo A, Bardan A et al. Increased serine protease activity and cathelicidin promotes skin inflammation in rosacea. Nat Med 2007; 13:975-80. 